\title{
On Carnitine Content of the Human Breast Milk
}

\author{
ATTILA SANDOR, ${ }^{(18)}$ KATALIN PECSUVAC, JANOS KERNER, AND ISTVAN ALKONYI
}

Institute of Biochemistry, University Medical School and County Children's Hospital, Pécs, Hungary

\begin{abstract}
Summary
The concentration of total carnitine in human breast milk remained at a constant mean level near 62.9 range: $56.0-69.8$ / nmoles/ml during the first 21 days postpartum. The carnitine level fell significantly to $35.2 \pm 1.26 \mathrm{nmoles} / \mathrm{ml}$ until the $40-50$ th day. The carnitine concentrations did not depend on the secreted volume of milk. In comparison, fresh and commercial pasteurized cow's milk contained 206.2 (range: 192-269) nmoles/ml and 160.0 (range: 158-200) nmoles/ml carnitine, respectively. In the sera of nursing mothers, the concentration of total carnitine was lower on the first day after delivery $(27.2 \pm 1.19 \mathrm{nmoles} / \mathrm{ml})$ but returned to normal by the 21 st day postpartum $(38.8 \pm 2.97$ nmoles $/ \mathrm{ml})$.
\end{abstract}

\section{Speculation}

Recently it has been reported that human and animal newborns need exogenous carnitine (10), which probably plays an important role in neonatal ketogenesis. The natural carnitine source for newborns is the mother's milk. Determining the relationship between days postpartum and carnitine concentration in breast milk makes possible an estimate of when the mother's milk is the optimal carnitine source.

In mammals the primary fuel for the fetus is maternal glucose. Immediately after birth, newborns must switch over to combustion of fat released from the adipose tissue (9) or derived from the mother's milk (4). As a consequence, the level of nonesterified fatty acids and ketone bodies rise rapidly in the newborn serum $(8,12,13)$. Ketone bodies produced by the liver serve as important fuel for extrahepatic tissues and as precursors for brain lipid synthesis (14). Carnitine, $\gamma$-trimethylamino- $\beta$-hydroxybutyrate, and carnitine palmitoyltransferase enzyme (CPT) EC 2.3.1.21 play a key role in fatty acid oxidation (3). They transport the activated fatty acids from the cytoplasm across the inner mitochondrial membrane barrier to the site of combustion. The hepatic carnitine level in rats (6) and both the carnitine level and CPT activity in developing rats $(2,12)$ correlate well with the ketogenic capacity of the liver. However, newborn rats (12) and human neonates (10) need exogenous carnitine supplement. Mother's milk is the most common carnitine source for babies. In rats, carnitine is shown to be transferred from the maternal liver to the neonatal tissues via milk of the mother animal (12). Human breast milk also contains carnitine in the range of $39-63$ nmoles $/ \mathrm{ml}(10)$. In rats, milk carnitine levels after birth sharply decrease within 10 days. This decrease is accompanied by a decline in hepatic carnitine and serum ketone body concentration in the baby rats (12). The question arises whether or not the carnitine level in human breast milk decreases just as quickly.

The present study follows carnitine levels in human breast milk during the period after delivery.

\section{MATERIALS AND METHODS}

Twenty-seven mothers delivering at term without any complication were involved in the investigations. The phrase, the 1st day refers to the day immediately after delivery. Milk samples of about
$2 \mathrm{ml}$ were collected directly from the mothers by manual expression in the presence of a member of the staff between 8:00 and 10: 00 A.M. The samples were taken before breast-feeding the baby, so the collected milk can be assumed "fore" milk. For comparison, in another set of experiments, "fore" and "hind" milk were taken from the same mothers at the sixth day postpartum. Daily volume of secreted milk was measured and recorded during hospitalization for 6 days. Daily volume refers to the sum of milk sucked by the baby (based on body-weighing) plus that which was expressed by the mother. (Mothers were encouraged to empty their breast as completely as possible.)

Fresh individual or pooled milk was also taken from the special Health Service. In this case the samples were stored at $5^{\circ} \mathrm{C}$ for no more than $6 \mathrm{hr}$. Pasteurization, when its effect was tested, was done in our laboratory.

Milk samples were stored at $-25^{\circ} \mathrm{C}$ and were analyzed in $1 \mathrm{wk}$. This storage did not have any effect on the total carnitine content. First, the samples were diluted with distilled water to twice the volume and then prepared for analysis of total carnitine as described by Parsons et al. (11). The alkaline hydrolysis in $0.2 \mathrm{~N}$ $\mathrm{KOH}$ was done at $37^{\circ} \mathrm{C}$ for $6 \mathrm{hr}$, instead of the recommended $60^{\circ}$ $\mathrm{C}$ for $2 \mathrm{hr}$. This way we could avoid the formation of too much caramel. Finally, the neutralized perchloric acid extracts were analysed for total carnitine. "Total carnitine" refers to the sum of esterified and free carnitine. The measurements were carried out by the radiochemical method (method A) according to McGarry and Foster (7) with the modification that we used N-ethylmaleinimide for trapping thiol groups. The moderate condition of alkaline hydrolysis made the samples suitable also for spectrophotometric carnitine assay (Method B) as described by Pearson et al. (11). Generally the radiochemical method has been considered more reliable. Therefore, the results obtained by Method A were statistically analysed.

The dry material was measured by storing the milk samples in a vacuum desiccator over $\mathrm{P}_{2} \mathrm{O}_{5}$ until reaching a constant weight.

Sera were prepared from heparinized venous blood. The hydrolysis and extraction were performed according to Reference 11. Total carnitine was determined by the radiochemical method (7). All radioactive samples were measured in Bray's solution by a Beckman LS 230 counter. For statistical analysis the Student's $t$ test was employed.

$\left[1^{14} \mathrm{C}\right]$-acetyl-coenzyme-A was obtained from the Radio-chemical Centre (Amersham). Carnitine acetyltransferase enzyme was attributed from Boehringer (Mannheim). Authentic L-carnitine, as standard, was a kind gift from Sigma-Tau (Rome). N-ethylmaleinimide and 5,5'-Dithio-bis(2-nitrobenzoic acid) (Ellman's reagent) were purchased from Fluka (Buchs).

\section{RESULTS}

It is seen in Table 1, that the carnitine level in the colostral human breast milk does not change for 6 days after delivery and ranges from 56.0 to $69.8 \mathrm{nmoles} / \mathrm{ml}$. At the $21 \mathrm{st}$ day postpartum the carnitine level falls into the same range, $58.7 \mathrm{nmoles} / \mathrm{ml}$. However, by the $40-50$ th day its level drops to $35.2 \mathrm{nmoles} / \mathrm{ml}$, which is half of the value that was observed during the first $3 \mathrm{wk}$. The change in the dry material content is so slight, that the same 
statements are valid for values calculated on dry material basis. It is also seen (Table 1) that values obtained by method B show the same trend at a somewhat lower level. Data in Table 1 were obtained from milk refered to as "fore" milk. In six other women we compared the "fore" and "hind" milk with respect to the carnitine content at the sixth day postpartum. The concentration of carnitine in the "fore" and "hind" milk was found to be 70.5 \pm 5.93 and $70.0 \pm 5.31$ nmoles $/ \mathrm{ml}$, respectively (data not shown).

To evaluate human milk as a carnitine supplier, it is important to know how the carnitine concentration changes at a later stage of lactation. More than two months after delivery the milk carnitine level was found to be $39.3 \pm 2.0$ nmoles $/ \mathrm{ml}$, so its level does not continue to decrease below the $40-50$ th day value. This average value in the later period can be calculated from the data in Figure 1. (see below in details). Furthermore, the carnitine content of the pooled mother's milk obtained from a Special Health Service is also close $(38.2 \mathrm{nmoles} / \mathrm{ml}$, Table 2$)$ to that of the 40-50th day milk.

Table 1. Carnitine content in human breast "fore milk" as a function of time after delivery

\begin{tabular}{|c|c|c|c|c|}
\hline \multirow{2}{*}{$\begin{array}{l}\text { Days post- } \\
\text { partum }\end{array}$} & \multicolumn{2}{|c|}{ Total carnitine (nmoles/ml) } & \multirow{2}{*}{$\begin{array}{c}\text { Dry material } \\
(\mathrm{g} / 100 \mathrm{ml})\end{array}$} & \multirow{2}{*}{$\begin{array}{c}\text { No. of } \\
\text { cases }\end{array}$} \\
\hline & Method A & Method B & & \\
\hline 1 & $\begin{array}{l}69.8 \pm 6.00 \\
(46.6-78.8)\end{array}$ & $66.1 \pm 5.68$ & $14.3 \pm 1.05$ & 6 \\
\hline 2 & $\begin{array}{l}62.3 \pm 5.34 \\
(48.8-77.3)\end{array}$ & $55.0 \pm 4.31$ & $13.9 \pm 1.12$ & 6 \\
\hline 3 & $\begin{array}{l}61.6 \pm 3.02 \\
(52.3-72.6)\end{array}$ & $54.1 \pm 1.86$ & $13.0 \pm 2.11$ & 6 \\
\hline 4 & $\begin{array}{l}67.7 \pm 4.65 \\
(53.8-87.4)\end{array}$ & $58.2 \pm 4.83$ & $13.2 \pm 2.71$ & 6 \\
\hline 5 & $\begin{array}{r}56.02 \pm 1.37 \\
(55.1-59.8)\end{array}$ & $45.1 \pm 3.51$ & $12.9 \pm 0.66$ & 5 \\
\hline 6 & $\begin{array}{r}64.32 \pm 5.58 \\
(51.5-81.9)\end{array}$ & $46.8 \pm 4.64$ & $13.0 \pm 1.08$ & 5 \\
\hline 21 & $\begin{array}{l}58.7 \pm 3.11 \\
(48.3-79.1)\end{array}$ & & $13.0 \pm 1.77$ & 6 \\
\hline $40-50$ & $\begin{array}{l}35.2 \pm 1.26 \\
(27.7-40.0)\end{array}$ & $21.3 \pm 3.00$ & $12.8 \pm 0.63$ & 8 \\
\hline
\end{tabular}

${ }^{1}$ Milk samples were assayed for total carnitine after alkaline hydrolysis by radiochemical (method A) and spectrophotometric (method B) methods. Values are expressed as mean \pm S.E. with the range in parentheses. Level of significance was found to be $P<0.001$ for all carnitine values obtained by method $A$ when they were compared to the $40-50$ day value.
The possible role of secreted milk volume on the carnitine concentration was tested during the first week postpartum and during the later stage of lactation. Daily volume on the second day postpartum was found to be $117.5 \mathrm{ml}$ (range: 70-211), gradually increased and reached $403.5 \mathrm{ml}$ (range: $240-640$ ) by the fifth day. Regarding the constant carnitine concentration in breast milk during this time, the increasing volume means that the mothers excreted increased amounts of carnitine. It is noteworty, that there was no individual correlation between the volume and carnitine concentration on the fifth day (not shown).

The role of volume in the later lactational stage was investigated in the mother's milk-collecting Health Service. The exactly measured quantity of milk delivered to the Service was used for calculations. The selected mothers bore 2-5 months ago and delivered milk daily from 150 to $2100 \mathrm{ml}$. Figure 1 shows that the volume did not have any effect on either the dry material or on the carnitine content of human breast milk.

For comparison, Table 2 shows the carnitine content of pooled mother's milk, cow's milk, cow's milk based formulas, and the effect of storage and pasteurization. The most striking result is the

Table 2. Comparison of the carnitine content of human milk, cow's milk, goat's milk, cow's milk based formulas and the effect of storage and pasteurization ${ }^{1}$

\begin{tabular}{lc}
\hline \multicolumn{1}{c}{ Carnitine source } & $\begin{array}{c}\text { Carnitine concentration } \\
(\mathrm{nmoles} / \mathrm{ml})\end{array}$ \\
\hline Pooled mother's milk $(\mathrm{PMM})^{2,3}$ & $38.2(100 \%)$ \\
PMM stored at $+5^{\circ} \mathrm{C}$ for $48 \mathrm{hr}^{2,3}$ & $34.2(90.4 \%)$ \\
PMM pasteurized & $37.2(97.6 \%)$ \\
PMM pasteurized and stored at $+5^{\circ} \mathrm{C}$ & $33.3(87.2 \%)$ \\
$\quad$ for $48 \mathrm{hr}^{2,3}$ & \\
Cow's milk, fresh $^{4}$ & $206.2(192-269)$ \\
Cow's milk pasteurized, commercial $^{4}$ & $162.0(158-200)$ \\
Milk of a goat $^{3}$ & 189.8 \\
Robolact $^{4,5}$ & $69.0(66.0-70.1)$ \\
Robebi A $^{4,5}$ & $77.2(68.1-80.2)$ \\
Robebi $^{4,5}$ & $60.5(59.2-62.2)$ \\
\hline
\end{tabular}

${ }^{1}$ Samples were assayed for total carnitine after alkaline hydrolysis with the radiochemical method (method $\mathrm{A}$ ).

${ }^{2}$ Supplied by the mother's milk-collecting Health Service. Percentage of the value of untreated milk is shown in parentheses.

${ }^{3}$ Value is the mean of two determinations on the same sample.

${ }^{4}$ Value is the mean of four separate samples with the range in parentheses.

${ }^{5}$ Commercial cow's milk based formulas in Hungary. The powders were dissolved according to the instructions.

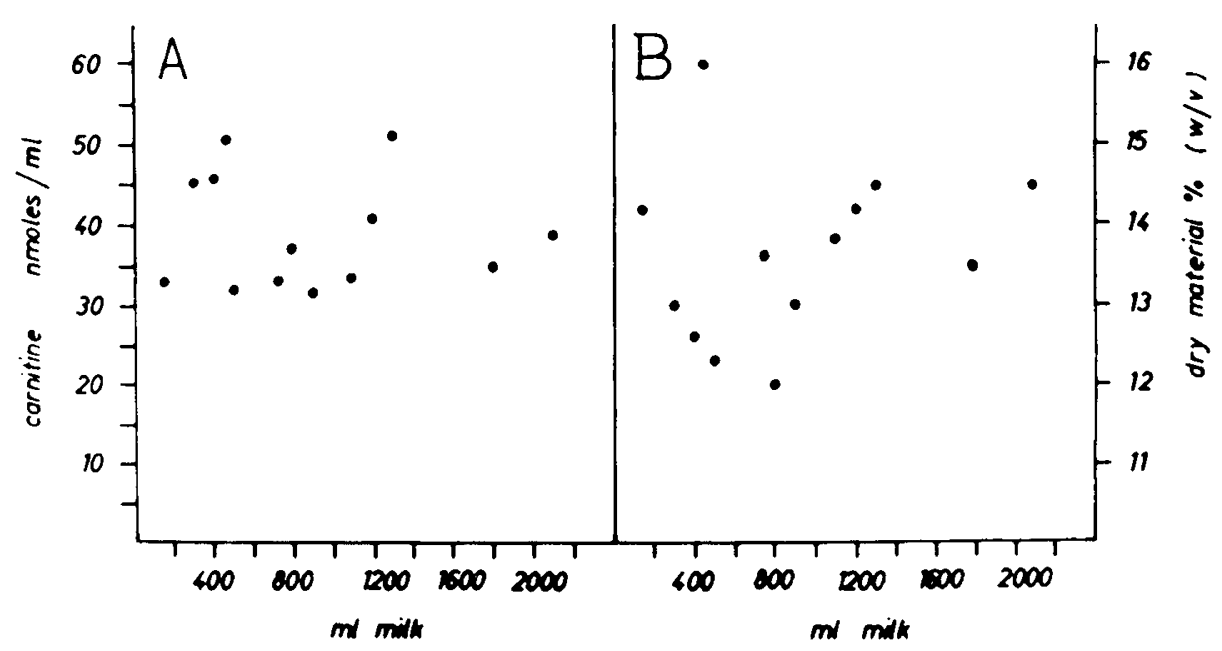

Fig. 1. The carnitine concentration $(A)$ and dry material content $(B)$ of human breat milk as a function of volume. Volume means the quantity of milk delivered by a donor to the mother's milk-collecting Health Service. Dry material \% (w/v) means g/l00 ml. Each point represents a donor woman. Total carnitine was determined after alkaline hydrolysis by the radiochemical (method A) method. 
Table 3. Carnitine concentration in human mother's serum as a function of time after delivery

\begin{tabular}{|c|c|c|c|c|c|}
\hline & \multicolumn{5}{|c|}{ Days postpartum } \\
\hline $\begin{array}{r}\text { Total carnitine } \\
(\mathrm{nmoles} / \mathrm{ml})\end{array}$ & $27.2 \pm 1.19$ & $28.6 \pm 1.16$ & $31.4 \pm 1.54$ & $38.8 \pm 2.97$ & $38.3 \pm 1.66$ \\
\hline Significance & $P<0.01$ & No & No & No & No \\
\hline No. of cases & 6 & 6 & 6 & 6 & 8 \\
\hline
\end{tabular}

${ }^{1}$ Sera were prepared from heparinized venous blood and assayed for total carnitine with the radiochemical method (method A) after alkaline hydrolysis. Values are expressed as mean \pm S.E. Differences between the values and the 40-50 day value were statistically evaluated.

following: how little carnitine occurs in the pooled mother's milk and even in the formulas when compared with cow's milk.

The carnitine level in the maternal sera is significantly low for normal female controls on the day after the delivery (Table 3). Then it gradually rises until the 21 st day postpartum. During the first 6 days postpartum we found that the haematocrit value remained at approximately $0.38 \pm 0.032$. The serum protein concentration increased from $64.1 \pm 5.58$ to $67.6 \pm 7.0 \mathrm{~g} /$ liter during this same period. All of these parameters fall in the lower part of the normal range, therefore, the haemodilution is unlikely responsible for the lower carnitine levels.

\section{DISCUSSION}

Human neonates (10) and animal newborns (12) maintain the carnitine level in their blood and tissues mainly by taking up carnitine from exogenous source. The carnitine level in the plasma of human infants fed a carnitine-free soybean based diet is much lower than that of infants fed milk (10). Because the organism partly depends on exogenous supplements, carnitine can be assumed as a vitamin-like compound at the early stage of development.

From the results, the carnitine concentration remains at its higher level for at least $3 \mathrm{wk}$ after delivery. This period surely overlaps neonatal ketogenesis, which subsides by the fifth-sixth days postpartum, whereas the elevated level of fatty acids lasts about for 1 year (8). From the end of the third wk, the carnitine level declines as outlined above. This time course suggests that milk carnitine can effectively promote neonatal ketogenesis, which is the period of intensive fat combustion. So, the carnitine levels occuring in breast milk during lactation may reflect the needs of infant.

The above relationships may be of importance for non-breastfed newborns. Human milk is commonly used for feeding premature and normal infants. Most often these infants are fed human milk collected and supplied by a special Health Service. However, this milk is collected from women who are in a later stage of lactation and their milk proves to be a poor carnitine supplier, as demonstrated in this work (Table 2). On the other hand, greater volumes collected from some donors are not at the expense of either the carnitine or dry material content (Fig. 1).

The carnitine concentration in mother's serum is significantly lower immediately after birth and returns to the normal female control value (1) by the 21 st day. Although this observation is in agreement with data from human studies $(1,5)$ and rats $(12)$, the reason is not yet clear. Perhaps, the lower carnitine level in the mother's serum may be related to the report that delivery can evoke crisis in patients suffering from carnitine deficiency (1). At any rate, the average value of milk carnitine concentration found during the first 21 days after delivery $(62.9 \mathrm{nmoles} / \mathrm{ml})$ is significantly higher $(P<0.001)$ than all serum carnitine values $(27.2-$ $38.8 \mathrm{nmoles} / \mathrm{ml}$ ) occurring during the same period. Most probably it is due to the active function of the mammary gland.

These considerations raise the issue whether or not to supplement human breast milk with carnitine to at least the level found in the early period of lactation or in the cow's milk based formulas. The relatively high carnitine content of the cow's milk gives additional support to the idea of supplementation. To know the full role of milk carnitine in infant nutrition we should also know the age until which children need exogenous carnitine and the quantity of demand. These parameters remain to be determined.

\section{REFERENCES AND NOTES}

I. Angelini, C., Govoni, E., Bragaglia, M. M., and Vergani, L.: Carnitine deficiency: acute postpartum crisis. Ann. Neurol., 4: 558 (1978).

2. Augenfeld, J., and Fritz, I. B.: Carnitine palmitoyltransferase activity and fatty acid oxidation by livers from fetal and neonatal rats. Can. J. Biochem., 48: 288 (1970)

3. Delisle, G., and Fritz, I. B.: Interrelations between hepatic fatty acid oxidation and gluconeogenesis: a possible regulatory role of carnitine palmitoyltransferase. Proc. Nat. Acad. Sci. USA, 58: 790 (1967).

4. Hahn, P., and Koldovsky, O.: Utilization of Nutritients During Postnatal Development. (Pergamon Press, Oxford, 1966).

5. Hahn, P., Skala, J. P., Seccombe, D. W., Frochlich, J., Penn-Walker, D., Novak, M., Hynie, D., and Towell, M. E.: Carnitine content of amniotic fluid and maternal and umbilical blood. Pediatr. Res., 11: 878 (1977).

6. McGarry, J. D., Robles-Valdes, C., and Foster, D. W.: Role of carnitine in hepatic ketogenesis. Proc. Nat. Acad. Sci. USA, 72: 4385 (1975).

7. McGarry, J. D., and Foster, D. W.: An improved and simplified radioisotopic assay for determination of free and esterified carnitine. J. Lipid Res., 17: 277 (1976).

8. Melichar, V., Drahota, Z., and Hahn, P.: Changes in the blood levels of acetoacetate and ketone bodies in newborn infants. Biol. Neonate, 8: 348 (1965).

9. Novak, M., and Monkus, E.: Metabolism of subcutaneous adipose tissue in the immediate postnatal period of human newborns. I. Developmental changes in lipolysis and glycogen content. Pediatr. Res., 6: 73 (1972).

10. Novak, M., Wieser, P. B., Buch, M., and Hahn, P.: Acetylcarnitine and free carnitine in body fluids before and after birth. Pediatr. Res., 13: 10 (1979).

11. Pearson, D. J., Tubbs, P. K., and Chase, J. F. A.: In H. V. Bergmeyer: Methods of Enzymatic Analysis; 2nd ed. p. 1758. (VeHag Chemie Weinheim, 1974).

12. Robles-Valdes, C., McGarry, J. D., and Foster, D. W.: Maternal-fetal carnitine relationships and neonatal ketosis in rat. J. Biol. Chem., 251: 6007 (1976).

13. Van Duyne, C. M., and Havel, R. J.: Plasma UFA concentration in fetal and neonatal life. Proc. Soc. Exp. Biol. Med., 102: 599 (1959).

14. Yu-Yan Yeh, Streuli, V. L., and Zee, P.: Ketone bodies serve as important precursors of brain lipids in developing rats. Lipids, 12: 957 (1977).

15. The present address of Dr. K. Pecsuvac is: County Children's Hospital, Pécs

16. The authors thank Dr Zoltan Szereday, head of the Department of Obstetrics and Gynaecology, County Hospital, Pécs.

17. Mothers were informed about the aim of investigation and written consents were obtained.

18. Requests for reprints should be addressed to: Dr A. Sandor, Institute of Biochemistry, University of Medical School, H-7624 Pécs, Szigeti ut 12. Hungary.

19. Received for publication July 15, 1980

20. Accepted for publication May 1, 1981. 